\title{
Using Film in Multicultural and Social Justice Faculty Development: Scenes from Crash
}

\author{
Paula T. Ross, MA; Arno K. Kumagal, MD; Terence A. Joiner, MD, MHSA; Monica L. Lypson, MD, MHPE
}

\begin{abstract}
We designed a faculty development workshop integrating scene excerpts from the Academy Award-winning movie Crash and active learning methods to encourage faculty participation and generate participant dialogue. The aims of this workshop were to enhance awareness of issues related to teaching in a multicultural classroom; stimulate discussion on teaching and learning about potentially contentious issues linked to race, ethnicity, religion, gender, geographical origin, and class; and expose faculty to the use of multimedia to facilitate discussion on topics of diversity and social justice. Twenty-five faculty attended 3 workshops in various venues, 18 of whom completed workshop evaluations. The workshop evaluation revealed that all participants believed that the scene excerpts and discussions helped them to reflect on their own attitudes toward race and diversity and felt better prepared to effectively facilitate classroom discussions on similar issues. This workshop is a useful tool for helping faculty to develop the skills and confidence to facilitate, manage, and stimulate discussions on controversial issues in multicultural education that may otherwise be avoided due to lack of expertise or experience.
\end{abstract}

Key Words: faculty development, multicultural education, multimedia

\section{Introduction}

The Institute of Medicine's report, Unequal Treatment: Confronting Racial and Ethnic Disparities in Health Care, highlighted the role health care providers play in addressing disparities in health care. ${ }^{1}$ In the United States, racial and ethnic minorities tend to receive lower quality health care than nonminorities, even when access-related factors such as insurance and income are accounted for. While many have focused on the structural causes of health care disparities (eg, access to health care, lack of insurance), health care disparities also arise during interactions between providers and patients as the result of the type of care and how care is delivered. The

Disclosures: The authors report none.

Ms. Ross: Research Area Specialist, Department of Health Education and Health Behavior, School of Public Health, University of Michigan; Dr. Kumagai: Associate Professor of Internal Medicine and Medical Education and Director, Family Centered Experience and Longitudinal Cases, University of Michigan Medical School; Dr. Joiner: Assistant Professor, Department of Pediatrics and Communicable Disease, University of Michigan Medical School; Dr. Lypson: Assistant Dean for Graduate Medical Education and Associate Professor of Internal Medicine and Medical Education, University of Michigan Medical School.

Correspondence: Paula T. Ross, Department of Health Education and Health Behavior, School of Public Health, 1415 Washington Heights, 3858 School of Public Health Building I, University of Michigan, Ann Arbor, MI 481092029; e-mail:paulat@umich.edu.

(c) 2011 The Alliance for Continuing Medical Education, the Society for Academic Continuing Medical Education, and the Council on Continuing Medical Education, Association for Hospital Medical Education. - Published online in Wiley Online Library (wileyonlinelibrary.com). DOI: $10.1002 / \mathrm{chp} .20126$ evidence supports two primary explanations for disparities arising from the medical encounter. The first is physician bias, which involves conscious or unconscious racial bias, prejudice, and patient stereotyping. Second is poor or ineffective communication; because doctor-patient interactions serve as a primary means for transmitting medical information, problems in cross-cultural communication may result in poor health outcomes. ${ }^{1-3}$ These explanations have led to calls to train more minority physicians in an effort to increase the frequency of racially concordant medical interactions. ${ }^{4,5}$ Racial concordance between patients and health care providers has been found to promote better communication, increase patient involvement in decision making, and improve patient satisfaction. ${ }^{6,7}$ However, given that the vast majority of patients of color are treated by health care professionals of a different race or ethnicity, calls to increase numbers of minority physicians have been accompanied by mandates to address physician bias and foster heightened awareness and sensitivity to other cultures and belief systems. ${ }^{1,6}$

Educational initiatives designed to address health care disparities and cross-cultural interactions have become a priority within medical school curricula in order to address the health care needs of an increasingly diverse and global population. ${ }^{7,8}$ Preparing medical students to address health care disparities based on visible and invisible social locations (eg, race/ethnicity, class, gender, and religion, sexual orientation) involves emphasizing both the epidemiologic and clinical aspects of patient care. ${ }^{9}$ However, we would argue that acquiring knowledge and developing communication skills, while necessary, are insufficient to effectively address issues of diversity, disparities, and social justice: this 
process also involves developing a critical consciousness of the ways in which our assumptions, biases, and prejudices influence physician-patient interactions. ${ }^{10,11}$ Many of these initiatives have utilized faculty or specialized facilitators to promote the development of students' cultural competency through the knowledge, skills, and attitudes framework using lectures, standardized patient exercises, and case-based discussions. Other methods, such as narratives, small-group exercises, vignettes, or reflective writing, have also been used. ${ }^{12}$ In teaching and learning about issues of diversity and social justice, documentaries and films ${ }^{13,14}$ may serve a particularly important role, for they use the power of narrative to enhance perspective-taking and empathy, and help learnersincluding faculty - to critically assess their own assumptions and biases in their "encounters with otherness." ${ }^{15,16}$ In a related context, we have previously used photography-based storytelling to stimulate critical reflection on issues of race, gender, and class in exploring the interactions of an individual artist with sickle cell disease with the health care system. ${ }^{17}$ These efforts all require a high level of faculty involvement and expertise.

As discussed in the literature of both medical education and adult postsecondary education, these efforts are fraught with educational risks and challenges, including reducing marginalized groups to stereotyped caricature; reduction of complex concepts, such as culture, to overly simplistic, twodimensional constructs; and resistance from both students and faculty to discussions of race, ethnicity, gender, sexual orientation, and socioeconomic class. ${ }^{18-21}$ It has also been suggested that adequate preparation for facilitating intergroup discussions must incorporate strategies to enhance facilitators' ability to stimulate reflection on the personal biases, values, and worldviews that students (and instructors) bring into the classroom in order to foster the level of awareness of societal problems and develop approaches to their solutions. ${ }^{22-24}$ Consequently, faculty development efforts have been undertaken in a variety of educational settings to enhance instructors' ability to enhance reflective approaches and facilitate discussions of these important issues. ${ }^{25,26} \mathrm{We}$ have previously described a faculty development workshop designed specifically to enhance skills in facilitating discussions on contentious topics in order to broaden instructors' sensitivity and awareness in this area. ${ }^{18}$ In this article, we build on our prior work and report on a workshop we recently created to achieve three aims: (1) enhance awareness of issues related to teaching in a multicultural classroom; (2) stimulate discussion on teaching and learning about potentially contentious issues linked to race, ethnicity, religion, gender, geographical origin, and class; and (3) expose faculty to the use of multimedia to facilitate discussion on topics of diversity and social justice.

\section{Description}

The purpose of the present study was to evaluate the impact of an interactive faculty development workshop using scenes from the Academy Award-winning movie Crash on faculty instructors' attitudes toward potentially difficult discussions on diversity and social justice. Crash has been used in other education and training settings to generate dialogue on social relations and has been found to be an effective framework for stimulating thoughtful discussion and challenging existing beliefs and assumptions. ${ }^{26-28}$ This film became well-known for capturing the subtleties and nuances of race relations, sexism, ethnic tensions, and socioeconomic barriers and drawing the audience into a context that simultaneously resists and reinforces commonly held stereotypes. ${ }^{27-30}$ Using the city of Los Angeles, California, as a backdrop, the film offers an exceptional opportunity to explore concepts of racial stereotypes, cultural hegemony, marginalization, and prejudice and to encourage rich discussion.

The workshop was developed using a train-the-trainer model. This model is generally used to prepare individuals to educate or care for others (eg, teachers, physicians, social workers, counselors) and has been found to be successful in meeting the educational needs of the health care system by increasing the knowledge and skills of providers. ${ }^{31-33}$ Recent evaluations of physician train-the-trainer programs indicate significant improvements in faculty knowledge and ability to teach specific content areas. ${ }^{32,34}$

The integration of film in medical education has proven to be effective in developing critical-thinking skills. ${ }^{35}$ Unlike traditional educational methods, films can be engaging and provide vivid images that are easily remembered, especially when they trigger emotions, and carefully selected films can serve as a training guide for active learning exercises. ${ }^{36-38}$ A review of the literature revealed that health educators have begun to incorporate popular films into their curricula for the teaching of psychosocial issues in medicine,${ }^{35}$ psychiatry, ${ }^{39}$ nursing, ${ }^{37}$ counseling, ${ }^{40}$ and dental education. ${ }^{41}$ They are also being used to increase self-awareness and stimulate dialogue in various types of learning. This research supports the idea that health care providers are more honest about their reactions to characters than real patients/people. ${ }^{38}$

In particular, we believed that Crash would create the state of "cognitive disequilibrium" that we have argued is essential to prompting reflection and enhancing critical awareness of oneself, others, and the world. ${ }^{42}$ Cognitive disequilibrium is the state of "unease" that occurs when one encounters identities, perspectives, feelings, or experiences that are unfamiliar and may provoke critical reflection on one's own and others' values, worldviews, and biases..$^{42}$ Based on their work with students, Nagda, Gurin, and Lopez ${ }^{43}$ suggested using classroom discussions, experiential activities, debriefings of those activities and discussions, and self-reflection to encourage the processing of new information, a deeper understanding and awareness of race relations and the dynamics of racism, and to help students explore the areas that create personal dissonance. Using Crash, we combined film, situated cognition, that is, placing learning within the context of real-life situations-and active learning principles to develop four paired scenes to illustrate the paradoxical 
relationship between victim and victimizer within a sociocultural context. ${ }^{44,45}$ We intentionally selected scenes that would provide multiple perspectives of the featured characters and evoke feelings of anxiety, dissonance, and discomfort. We have used a similar approach in faculty development and learning experiences to stimulate critical discussions on race, ethnicity, gender, sexual orientation, and socioeconomic class. $^{10,16}$

The selected scenes are as follows:

- Scene 1. (Part 1) An Iranian immigrant and his daughter are seeking to purchase a firearm from a Caucasian pawnshop owner. The pawnshop owner falsely categorizes the immigrant's heritage and engages in a derogatory dialogue, making sexually explicit remarks to the daughter and ethnically insulting remarks to the father. (Part 2) The immigrant attempts to use the purchased firearm to seek revenge on a Mexican locksmith whom he believes is the perpetuator of a recent robbery of his store.

- Scene 2. (Part 1) Two young African American men are engaged in a discussion about inter- and intragroup discrimination. Although one believes such feelings are unsubstantiated, they subsequently carjack a luxury SUV from a Caucasian couple. (Part 2) One of the men carjacks a van with nearly a dozen Asians who are victims of human trafficking. Assuming they are Chinese, the man releases them in the heart of Chinatown.

- Scene 3. (Part 1) A middle-class Caucasian man, attempting to seek relief for his father, who is suffering from pain and urological issues, telephones his health maintenance organization for guidance. He speaks with an administrator, an African American woman, whom he believes is being unnecessarily uncooperative and unwilling to grant exceptions to existing policy. (Part 2) In his frustration, he attributes her lack of cooperation to her ethnicity as determined by her name and she hangs up on him. The next day, the son visits the administrator, who admits it is at her discretion to grant his request; however, in light of their recent interaction, she stands and denies the request. During this conversation the son insults the manager, stating that she acquired her position due solely to Affirmative Action hiring practices. The manager eventually has security escort him from her office.

- Scene 4. (Part 1) An affluent African American couple are stopped by two Caucasian police officers. During the stop, one of the officers sexually assaults the wife. With the looming threat of arrest or, worse, police brutality or death, the husband is left helpless to defend his wife. The following scene depicts the tension at home given the husband's lack of effort to rise to his wife's defense. (Part 2) Upon their arrival home, the wife is eager to report the incident to the authorities and expresses her frustration for the husband's decision to acquiesce to the "search." (Part 3) The husband refuses to succumb to the demands of a carjacker, causing a high-speed chase throughout several blocks. Again, the husband is stopped by two police officers; however, this time the husband refuses to cooperate. The police officer who witnessed the events in Part 1 attempts to defuse the situation with his new partner and convinces the other officer to let the husband go with a warning.

Each of the selected scenes addresses topics that we felt were relevant to the genesis and perpetuation of disparities in health care, addressing issues of privilege, prejudice, stereotyping, racial profiling, racism, and sexism. However, although these issues may be points of great contention, these topics were not chosen with the idea that issues of diversity are problems to be "managed" or resolved; instead, we posit that exploration of issues of diversity can deepen and enrich dialogues on American society. These scenes were then coupled with a specific active learning technique (eg, reflective writing, a fishbowl exercise) and subsequent discussion (see TABLE 1). Faculty were asked to share their impressions of the characters and situations and identify the contentious and emotional issues that created the situation in order to explore their own personal and professional experiences and engage in active discussion and reflection. ${ }^{24,46,47}$ We requested that workshop participants view the movie in its entirety prior to attending the workshop. We believed that while not critical, having some level of understanding of the context of the scenes had a potential benefit. Most important, the workshop attempted to engage participants in interactions - around scenes from the movie-that model the type of interactive discussions and critical reflection that we want participants to foster among their students. This workshop was designed to last approximately 1.5-2 hours. Workshop materials are available online. ${ }^{48}$

\section{Evaluation}

Three workshops were offered at various regional, national and international conferences. ${ }^{49-51}$ Twenty-five faculty attended, 18 of whom completed the anonymous workshop evaluations; 6 participants from the first workshop, 4 from the second, and 8 from the third. Participants were asked to complete an evaluation form after viewing the film excerpts and participating in the discussions and other activities. Evaluation questions were geared toward capturing faculty feelings regarding benefits of discussions of race and diversity. Since the purpose of this workshop was to stimulate a state of cognitive disequilibrium, we also asked participants how they felt about conflict in the classroom setting and various strategies to maintain effective classroom dialogue in spite of conflict. The evaluation consisted of both closed- and open-ended questions. As part of the Scene 2 exercise, participants were asked to respond to three questions designed to help them identify the situations and key themes. Reflective writing exercises provide a source of narrative documentation of learning outcomes. ${ }^{47,52,53}$ We used their responses to this exercise as another type of evaluation data.

\section{Quantitative Results}

Participants reported mixed feelings regarding the use of conflict in classroom discussions to stimulate productive discussions of race, with $44 \%$ indicating a neutral response. Sixty-one percent of the participants responded that they were reluctant to discuss issues of race and class because of possible conflicts, $39 \%$ reported that disagreement in 
TABLE 1. Workshop Activities

\begin{tabular}{|c|c|c|c|c|}
\hline Scene & Workshop Scene Titles & Format/Length & Active Learning Technique & Concepts Explored \\
\hline & Introduction & $\begin{array}{l}\text { Open discussion } \\
\quad(5 \text { minutes })\end{array}$ & $\begin{array}{l}\text { Workshop overview and Ground } \\
\text { rules for safe discussion }\end{array}$ & $\begin{array}{l}\text { Teaching in small groups on issues } \\
\text { related to disparities and cultural } \\
\text { competency }\end{array}$ \\
\hline 1 & $\begin{array}{l}\text { Pawn Shop } \\
\text { Attempted Shooting }\end{array}$ & $\begin{array}{l}\text { Open discussion } \\
\text { (10 minutes })\end{array}$ & $\begin{array}{l}\text { Large group discussion on scene } \\
\text { reflections }\end{array}$ & $\begin{array}{l}\text { Language barriers, immigration, } \\
\text { stereotyping, victim becoming the } \\
\text { victimized }\end{array}$ \\
\hline 2 & $\begin{array}{l}\text { Blind Fear } \\
\text { Freeing the Slaves }\end{array}$ & $\begin{array}{l}\text { Reflective writing } \\
\qquad(10 \text { minutes })\end{array}$ & $\begin{array}{l}\text { Writing exercise } \\
\text { Between } 3 \text { and } 10 \text { minutes spent } \\
\text { writing reflections especially } \\
\text { focused on the affective domain } \\
\text { (feelings evoked by these scenes) } \\
\text { Discuss reflections in small groups of } \\
3-5\end{array}$ & $\begin{array}{l}\text { Generalizations, stereotypes, } \\
\text { intragroup profiling, racism }\end{array}$ \\
\hline 3 & $\begin{array}{l}\text { Telephone Conversation } \\
\text { Meeting With Insurance } \\
\text { Manager }\end{array}$ & $\begin{array}{l}\text { Small-group } \\
\text { interactions/Pair-sharing } \\
\text { (10 minutes })\end{array}$ & $\begin{array}{l}\text { Discuss reflections in small groups } \\
\text { of } 2-3\end{array}$ & $\begin{array}{l}\text { Assumptions, profiling, privilege, } \\
\text { Affirmative Action }\end{array}$ \\
\hline 4 & $\begin{array}{l}\text { First Traffic Stop } \\
\text { Bedroom Conversation } \\
\text { Second Traffic Stop }\end{array}$ & $\begin{array}{l}\text { Fishbowl* } \\
\qquad(30 \text { minutes) }\end{array}$ & $\begin{array}{l}\text { View scenes } \\
\text { Explanation ( } 5 \text { minutes) } \\
\text { Inside Response (10 minutes) } \\
\text { Outside Response (15 minutes) }\end{array}$ & $\begin{array}{l}\text { Racial profiling, (dis)empowerment, } \\
\text { sexism, racism }\end{array}$ \\
\hline
\end{tabular}

*The version of the fishbowl technique applied to this study used gender-based groups (eg, women) who sat in a circle (the "fishbowl") and discussed their responses to the film while the men silently listened. ${ }^{58}$

classroom discussions made them feel uncomfortable, and $61 \%$ believed conflict between racial/ethnic groups makes it difficult to communicate with each other (See TABLE 2). Despite their feelings of discomfort, $72 \%$ of participants indicated it was more important for small-group members to challenge each other's beliefs than for to group members to get along. Additionally, given several options for handling conflict in the classroom, should it arise, 57\% stated they would ask students to continue conversation, but in a more respectful manner; $78 \%$ reported they would use a personal experience to get students to understand a different perspective; and 39\% indicated they would continue the conversation rather than avoiding the discussion (see TABLE 2).

Questions about the workshop specifically revealed that all participants believed that the scene excerpts and subsequent discussions helped them to reflect on their own attitudes toward race and diversity. Seventy-eight percent reported that the workshop would help them better understand the perspectives of their students, and $89 \%$ indicated that being confronted with unfamiliar perspectives and situations helped them to reflect on issues of race and diversity in US society.

\section{Qualitative Results}

Open-ended evaluation questions inquired specifically about how the scenes from the movie or the workshop affected the participants' perspectives on the topics discussed (see TABLE 3). In asking faculty which portion of the workshop they were likely to include in their own discussions of race, the fishbowl activity was the most frequently cited. This may be because of its ability to capture the varying perspectives, something the participants reported valuing. This technique specifically allows for expression and witnessing of conversations that may occur within a specific group, as opposed to attempting to tap into an intragroup dialogue within a heterogeneous group.

Faculty members often considered the reflective writing exercise to be particularly novel. Although reflective writing, along with other reflective techniques, has been widely used in medical educational settings to assess the humanistic and professional reflections of medical students, ${ }^{36,54,55}$ many of our participants had not experienced such activities as part of their medical training. Moreover, having faculty engage in a writing exercise helped to demonstrate the potential impact such an exercise could have on their students because 
The scenes from the movie Crash helped me to reflect on my own attitudes toward race and diversity.
The discussion of the movie Crash helped me to reflect on my own attitudes toward race and diversity.
I am comfortable using conflict in classroom discussions to stimulate productive discussions on issues
of race.

I am reluctant to discuss issues of race and class because of possible conflicts, which may arise.

I think conflict between racial/ethnic groups makes it difficult for them to communicate with each other.

I believe that it is more important for small group members to get along than to challenge each other's beliefs.

Being confronted with unfamiliar perspectives and situations helped me to reflect on issues of race and diversity in US society.

Disagreements in classroom discussions make me uncomfortable.

I believe this workshop will help me to better understand the perspectives of my students.

I would ask the students to continue the conversation, but in a more respectful manner.

I would immediately discontinue class/conversation to allow the students a chance to cool down.

I would use a personal experience to get the students to understand a different perspective
$18(100)$

$18(100)$

7 (38.9)

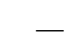

$8(44.4)$

$3(16.7)$

$4(22.2)$

$3(16.7)$

$11(61.1)$

$11(61.1)$

$1(5.6)$

$6(33.3)$

$3(16.7)$

$2(11.1)$

$13(72.2)$

$16(88.9)$

$2(11.1)$

$6(33.3)$

$5(27.8)$

$7(38.9)$

$14(77.8)$

$4(22.2)$

10 (55.6)

$2(11.1)$

$6(33.3)$

$5(27.8)$

$5(27.8)$

$7(38.9)$

$14(77.8)$

*Includes strongly agree and agree.

${ }^{\dagger}$ Includes strongly disagree and disagree.

narrative writing is one method of promoting critical thinking among learners. ${ }^{52,53}$

From their responses to the Scene 2 reflective writing exercise (see TABLE 4), it was evident that the activity prompted participants to reflect on issues such as race, prejudice, violence, anger, and interpersonal interactions. In a recent study using Crash with adult learners (faculty and graduate students), participants reported that the process made them think about race relations in more complex ways. ${ }^{56}$ Many of the Caucasian participants noted that the film caused them, in the words of one participant, to "look inward at themselves in different ways, and to look at some of their own prejudice." Similar to our findings, participants in this study also reported that the power of the film caught them off guard and caused them to think about issues in new ways and reconsider their own views and attitudes toward others.

\section{Conclusion}

We developed a faculty development workshop designed to assist faculty in facilitating discussions on race, gender, sexual orientation, and socioeconomic diversity. The feedback we received suggests that the professional development workshop is a useful tool for helping faculty to stimulate discussions on controversial issues in multicultural education that may otherwise be avoided due to lack of expertise or experience. Although a preworkshop attitudinal survey was not administered, responses to the postworkshop evaluation suggested an increased level of confidence with future classroom discussions on issues of multiculturalism. These results suggest that active learning tools may prove effective in helping faculty to constructively address dilemmas on similar topics.

Admittedly, the impact of the workshop on the actual skills of faculty to facilitate these types of discussions is not known, since the evaluation solicited self-reports of the faculty's engaging in critical reflection and their level of comfort and attitudes about facilitating discussions on diversity and social justice. To assess impact on actual teaching, longitudinal observations of instructors' small-group facilitation skills, as well as development of an effective means to judge pre- and postintervention levels of skill, would be necessary. Nonetheless, if the intention in these activities is to stimulate faculty critical reflection so that the type of critical consciousness we aim to foster in learners is modeled in faculty instructors, the workshop appeared to help demonstrate to the faculty ways in which this goal may be achieved.

A single faculty development workshop cannot be expected to respond adequately to years of hidden bias, nor can it provide all of the necessary training for faculty to facilitate discussions on contentious issues involving diversity, disparities, and social justice. This workshop attempts to bring bias to the forefront and give faculty some basic tools to deal with issues of prejudice that arise in student groups. It should be considered as part of an ongoing effort in faculty development in multicultural education that emphasizes the development of a critical awareness of disparities and a commitment to address social injustice. ${ }^{10}$ On a larger societal level, educational efforts to foster critical reflection are 
TABLE 3. Evaluation-Qualitative Responses

What was, for you, the most important things you learned from the movie?

How did the movie change your views on race (if at all)?

What was, for you, the most important things you learned from the workshop?

How did the workshop change your views on race (if at all)?

What aspects of the workshop would you like to incorporate into your facilitation of discussions of diversity?
To evoke emotional discussions that guide discussion.

Think about stereotypes and not make judgments.

Stereotypes is from a point of ignorance and comfort.

Everyone has assumptions.

The evolving nature of target (victim) and agent (victimizer).

Stereotyping - we need to be so mindful.

Not really any changes (too "liberal").

How fear plays a big role in conflict.

Do not make assumptions.

Everyone is a potential victim ad victimizer of discrimination and profiling.

The power of facilitating or guiding uncomfortable conversations/discussion.

We have to understand each other.

The movies sets the stage but the discussion clarified issues and generated a broader view of issues.

Everyone has a perspective on the other that may be misinformed.

Film, techniques, fishbowl.

Use higher risk activities in briefer educational activities.

Combinations of all we did.

All of it.

Use of film clips.

I would like to urge all in faculty development on training to teach and be aware of cultural issues in health care.

The film and discussion questions to help my faculty reflect.

TABLE 4. Scene 2 Reflective Writing Exercise Responses

Describe in several sentences your reflections on the issues portrayed in these scenes.

List the three most striking themes that arise from this pair of scenes below.

What is the connection between these two scenes?
Everyone is looking at the world through different lenses. Sometimes ones actions are not good but that doesn't mean that the "whole" person is bad.

Real-life situations and the problems faced in day-to-day life in certain parts of the world.

The duality of experiencing again feeling victimized/discriminated against but then fulfilling the stereotype and then later changing that perspective again -potentially doing what may be viewed as "good" but motives challenge was the rationality of the discussion contrasting against the extreme action.

No one is wholly good or bad.

Anger leads to crimes lack of appreciation for human life and property.

We must respond to the actual behavior that things change and are situational.

A victim of stereotype partakes of stereotyping.

Spend time to get to know people.

Triangulation, persecuted, doer, savior, victim.

Sense of imprisonment and to escape being difficult. 


\section{Lessons for Practice}

- With the experience gained from this workshop, participants acquired examples of how to facilitate similar small-group discussions in which they can engage medical students in active, engaged reflection and discussion of societal issues in the practice of medicine.

- This workshop is a unique tool for getting faculty to reflect on their own attitudes toward race and diversity (eg, race, socioeconomic status, gender) by capturing their interest and involvement.

- This workshop also provides faculty with an opportunity to discuss how best to manage opposing opinions and difficult topics in the classroom environment.

meant to directly address one of the major putative causes for race-based disparities in the delivery of health careunexamined personal biases, assumptions, and beliefs on the part of health care providers. Therefore, activities such as the one described in the current study should contribute to improving patient care in a diverse and often unequal society. ${ }^{8,10}$ We believe that use of narrative and experiential learning has the potential to serve this purpose. ${ }^{57}$

\section{References}

1. Smedley BD, Stith AY, Nelson AR. Unequal Treatment: Confronting Racial and Ethnic Disparities in Health Care. Washington, DC: Institute of Medicine of the National Academies; 2002.

2. Malat J. Expanding research on the racial disparity in medical treatemnt with ideas from sociology. Health. 2006;10(3):303-321.

3. Ashton CM, Haidet P, Paterniti DA, et al. Racial and ethnic disparities in the use of health services: bias, preference, or poor communication? J Gen Intern Med. 2003;18(2):146-152.

4. Cohen JJ, Gabriel BA, Terrell C. The case for diversity in the health care workforce. Health Aff. 2002;21(5):90-102.

5. Reede JY. A recurring theme: The need for minority physicians. Health Aff. 2003;22(4):91-93.

6. Liaison Committee on Medical Education. Structure for Accreditation of Medical Education Programs Leading to the MD Degree: Functions and Structure of a Medical School. Washington, DC: Liaison Committee on Medical Education; 2008.

7. Vela MB, Kim KE, Tang H, Chin MH. Innovative health care disparities curriculum for incoming medical students. J Gen Intern Med. 2008;23(7):1028-1032.

8. Smith WR, Betancourt JR, Wynia MK, et al. Recommendations for teaching about racial and ethnic disparities in health and health care. Ann Intern Med. 2007;147(9):654-665.

9. Branch WT, Kern D, Haidet P. Teaching the human dimensions of care in clinical settings. JAMA. 2001;286(9):1067-1074.

10. Kumagai AK, Lypson ML. Beyound cultural competence: critical consciousness, social justice and multicultural education. Acad Med. 2009;84(6):782-787.
11. Gates M, Bradley KD. Measuring cross-cultural competence in medical education: a review of curricular effectivness and attitudinal studies. Paper presented at the annual meeting of the American Educational Research Association, San Diego, CA, April 12-18, 2009.

12. DasGupta S, Charon R. Personal illness narratives: using reflective writing to teach empathy. Acad Med. 2004;79(4):351-356.

13. Grainger-Monsen M, Haslett J. Worlds Apart: A Four Part Series on Crosscultural Health Care. Harriman, NY: Fanlight Productions; 2005.

14. Unnatural causes: Is inequality making us sick? San Francisco, CA California Newsreel and Vital Pictures; 2008.

15. Daloz LAP. Transformative learning for the common good. In: Mezirow J, ed. Learning as Transformation: Critical Perspectives on a Theory in Progress. San Francisco, CA: Jossey-Bass, 2000:103-123.

16. Kumagai AK, White CB, Ross PT, Purkiss JA, O'Neal CM, Steiger JA. Use of interactive theater for faculty development in multicultural education. Med Teach. 2007;29(4):335-340.

17. Ross PT, Davis HL, Kumagai AK, Campbell AD, Lypson ML. Sickle cell vision: A patient's photographic illustration of coping. Acad Med. 2010;85(7):1210-1211.

18. Chan CS, Treacy MJ. Resistance in multicultural courses: Student, faculty, and classroom dynamics. Amer Behav Sci. 1996;40(2):212-221.

19. Gregg J, Saha S. Losing culture on the way to competence: The use and misuse of culture in medical education. Acad Med. 2006;81(6):542547.

20. Murray-Garcia J, Harrell S, Garcia J, Gizzi E, Simms-Mackey P. Selfreflection in multicultural training: be careful what you ask for. Acad Med. 2005;80(7):694-701.

21. Tatum BD. Talking about race, learning about racism: The application of racial identity development theory in the classroom. Harvard Educ Rev. 1992;62(1):1-8.

22. Garmon MA. Six key factors for changing perservice teachers' attitudes/beliefs about diversity. Educ Studies. 2005;38(3):275-286.

23. Ross PT, Cene CW, Bussey-Jones J, et al. A strategy for improving health disparities in medicine. J Gen Intern Med. 2010;25(Suppl 2):160163.

24. Gay G, Kirkland K. Developing cultural critical consciousness and self-reflection in preservice teacher education. Theory Pract. 2003;42(3):181-187.

25. Skelton JR, Kai J, Loudon RF. Cross-cultural communication in medicine: questions for educators. Med Educ. 2001;35(3):257-261.

26. Vallalba JA, Redmond RE. Crash: using a popular film as an experiential learning activity in a multicultural counseling course. Couns Educ Supervision. 2008;47(4):264-276.

27. Kinefuchi E, Orbe M. Situating oneself in a racialized world: understanding student reactions to Crash through standpoint theory and context-positionality frames. J Int Intercult Comm. 2008;1(1): $70-90$.

28. Orbe MP, Kinefuchi E. Crash under investigation: Engaging complications of complicity, coherence, and implicature through critical analysis. Crit Studies Media Comm. 2008;25(2):135-156.

29. Guy TC. Learning who we (and they) are: popular culture as pedagogy. New Direct Adult Contin Educ. 1997;115:15-23.

30. Matthews MR. "You think you know who you are ... you have no idea": critical reflections on the movie Crash. J Intergroup Relations. 2005/2006;32:96-101.

31. Stratos G, Katz S, Bergen M. Faculty development in end-of-life care: evaluation of a national train-the-trainer program. Acad Med. 2006;81:1000-1007.

32. Green M. A train-the-trainer model for integrating evidence-based medicine training into podiatric medical education. J Am Podiatr Med Assoc. 2005;95(5):497-504.

33. Burr C, Storm D, Gross E. A faculty trainer model: increasing knowledge and changing practice to improve perinatal HIV prevention and care. AIDS Pat Care STDs. 2006;20(3):183-192.

34. Corelli R, Fenlon C, Kroon LA, Prokhorov AV, Hudmon K. Evaluation of a train-the-trainer program for tobacco cessation. Am J Pharm Educ. 2007;71(6):1-9. 
35. Blasco PG. Literature and movies for medical students. Fam Med. 2001;33(6):426-428.

36. Self DJ, Baldwin DC. Teaching medical humanities through film discussions. J Med Humanit. 1990;11(1):23-37.

37. Higgins JA, Dermer S. The use of cinema in marriage and family counselor education. Couns Educ Supervision. 2001;40(3):183-193.

38. Alexander M. A review of the literature. In: Alexander M, Lenahan P, Pavlov A, eds. Cinemeducation: A Comprehensive Guide to Using Film in Medical Education. Oxford, England: Radcliffe; 2005:3-7.

39. Hyler S, Schanzer B. Using commercially available films to teach about borderline personality disorder. Bull Menninger Clin. 1997;61(4):458468.

40. Lowman J. Mastering the Techniques of Teaching. San Francisco, CA: Jossey-Bass; 1984.

41. Lockhart PB, Alexander M, Pettice YL, Olser RA. Behavioral medicine training in postdoctoral dentist education. J Dent Educ. 1992;56(3):209-213.

42. Piaget J. The Equilibration of Cognitive Structures: The Central Problem of Intellectual Development. Chicago, IL: University of Chicago Press; $1975 / 1985$.

43. Nagda BA, Gurin P, Lopez GE. Transformative pedagogy for democracy and social justice. Race Ethn Educ. 2003;6(2):165-191.

44. Choi J-I, Hannafin M. Situated cognition and learning environments: roles, structures, and implications for design. Hum Soc Sci Law. 1995;43(2):53-69.

45. Pololi L, Clay MC, Lipkin M, Hewson M, Kaplan C, Frankel RM. Reflections on integrating theories of adult education into a medical school faculty development course. Med Teach. 2001;23(3):276-283.

46. Steinert Y. Faculty development in the new millennium: key challenges and future directions. Med Teach. 2000;22(1):44-50.

47. Bonwell CC, Eison JA. Active Learning: Creating Excitement in the Classroom. ASHE-ERIC Higher Education Report No. 1. Washington, DC: George Washington University; 1991.
48. Lypson ML, Ross PT, Joiner TA, Kumagai AK. Using multimedia in faculty development on multicultural education: scenes from the movie Crash. MedEdPORTAL. 2010.

49. Lypson ML, Ross PT, Joiner TA, Kumgai AK. Using Multimedia in Faculty Development in Multicultural Education: Scences From the Movie Crash. Boston, MA: Generalists in Medical Education; 2009.

50. Lypson ML, Ross PT, Joiner TA, Kumgai AK. Using Multimedia in Faculty Development in Multicultural Education: Scenes From the Movie Crash. Chicago, IL: Central Group on Educational Affairs; 2010.

51. Ross PT, Joiner TA, Kumagai AK, Lypson ML. Using Multimedia in Faculty Development in Multicultural Education: Scences From the Movie Crash. Miami, FL: 14th Ottawa Conference on the Assessment of Competence in Medicine and the Healthcare Professions; 2010.

52. Kennison MM, Misselwitz S. Evaluating reflective writing for appropriateness, fairness, and consistency. Nurs Educ Perspect. 2002;23(5):238242.

53. Cooper NJ. The use of narrative in the development of critical thinking. Nurs Educ Today. 2000;20(7):513-518.

54. Wald HS, Reis SP. Beyond the margins: reflective writing and development of reflective capacity in medical education. J Gen Intern Med. 2010;25(7):746-749.

55. Shapiro J, Kasman D, Shafer A. Words and wards: a model of reflective writing and its uses in medical education. J Med Humanit. 2006;27(4):231-244.

56. Tisdell EJ. Critical media literacy and transformative learning: drawing on pop culture and entertainment media in teaching for diversity in adult higher education. J Transform Educ. 2008;6(1):48-67.

57. Cooper JE, Chattergy V, eds. Developing Faculty Multicultural Awareness: An Examination of Life Roles and Their Cultural Components. Stillwater, OK: New Forums Press; 1993.

58. Gall MD, Gillett M. The discussion method in classroom teaching. Theory Pract. 1980;19(2):98-103. 